\title{
Coordination by registered dieticians for nutritional and dietary support in disaster in Japan
}

\author{
Hiroki Yanagihara, ${ }^{a}$ Yuko Hatakeyama ${ }^{a}$ and Takashi Iwasaki ${ }^{a}$ \\ Correspondence to Hiroki Yanagihara (e-mail: h-yanagihara@pref.iwate.jp).
}

Problem: Yamada, a town of Iwate Prefecture in north-eastern Japan, was struck by the tsunami from the Great East Japan Earthquake. In Yamada, it was challenging to manage nutritional and diet support for food aid because these services were unavoidably drawn out for several months in evacuation shelters.

Context: In Japan, food aid in disasters is often provided, divided and distributed erratically due to poor efforts made with regards to dietary support from the perspective of nutrition. The need for nationally registered dieticians to coordinate nutritional and dietary support in evacuation shelters was considered in this disaster.

Action: A dietary support team was formed of nationally registered dieticians to study the dietary conditions of evacuees in shelters in Yamada and to develop a system to ensure the nutritional and balanced dietary needs of the evacuees.

Outcome: In this disaster response, model menus were prepared and a menu-food matching system was put in place to order and distribute foods required for balanced meals. Every effort was made to avoid excesses and deficiencies in nutrition; the meals consisted of a staple, main dish, side dish and soup. Along with that, food sanitation and stock management were improved.

Discussion: The menu-food matching system put together by the nationally registered dieticians was useful for nutritional and dietary support in this particular disaster. It is recommended that similar nutritional and dietary support coordinated by nationally registered dieticians be considered for disaster management plans where appropriate.

\section{PROBLEM}

Yamada is a farming, fishing and lumber town of 18957 people with an area of $26345 \mathrm{~km}^{2}$ located roughly in the middle of the Rikuchu Coast of Iwate Prefecture in northeastern Japan (Figure 1). On 11 March 2011, the Tohoku area of Japan was hit by a massive 9.0-earthquake and ensuing tsunami. In Yamada, the death and missing person toll from the earthquake and tsunami reached 779 as of 4 November 2011. As of 14 March 2011 some 6000 persons were still living in a total of 35 evacuation shelters.

In Yamada, the distribution of goods was hampered by collapsed buildings, severed utilities such as electricity, water and gas and disrupted road networks. Until services were restored and living in shelters was brought to an end, evacuees depended greatly on the government to prepare them food or provide them with food and cooking equipment. Yamada officials provided these services by procuring emergency stores and relief supplies, but it was challenging to manage nutrition and diet support for food aid because these services were unavoidably drawn out for several months.

\section{CONTEXT}

If a large-scale natural disaster or other major emergency strikes Japan, the nation, prefectures and municipalities are assigned roles within the disaster management plans formulated under the Disaster Countermeasures Basic Act. As a part of disaster response efforts, municipalities are responsible for procuring and supplying food as dietary support for evacuees. When needed, municipalities request prefectures to procure, transport, store, supply, regulate supply and demand of and prepare food provisions. Because the supply, division and distribution of food to evacuees are erratic and disaster management departments are overburdened with assignments in municipal disaster management plans, dietary support has not been addressed from a nutritional

aiyako Public Health Center, Iwate Prefecture, Japan

Submitted: 11 November 2011; Published: 16 May 2012

doi: $10.5365 /$ wpsar.year.2011 1.2.4.011 


\section{Figure 1. Miyako Public Health Center area of jurisdiction and Yamada, Iwate Prefecture, Japan}

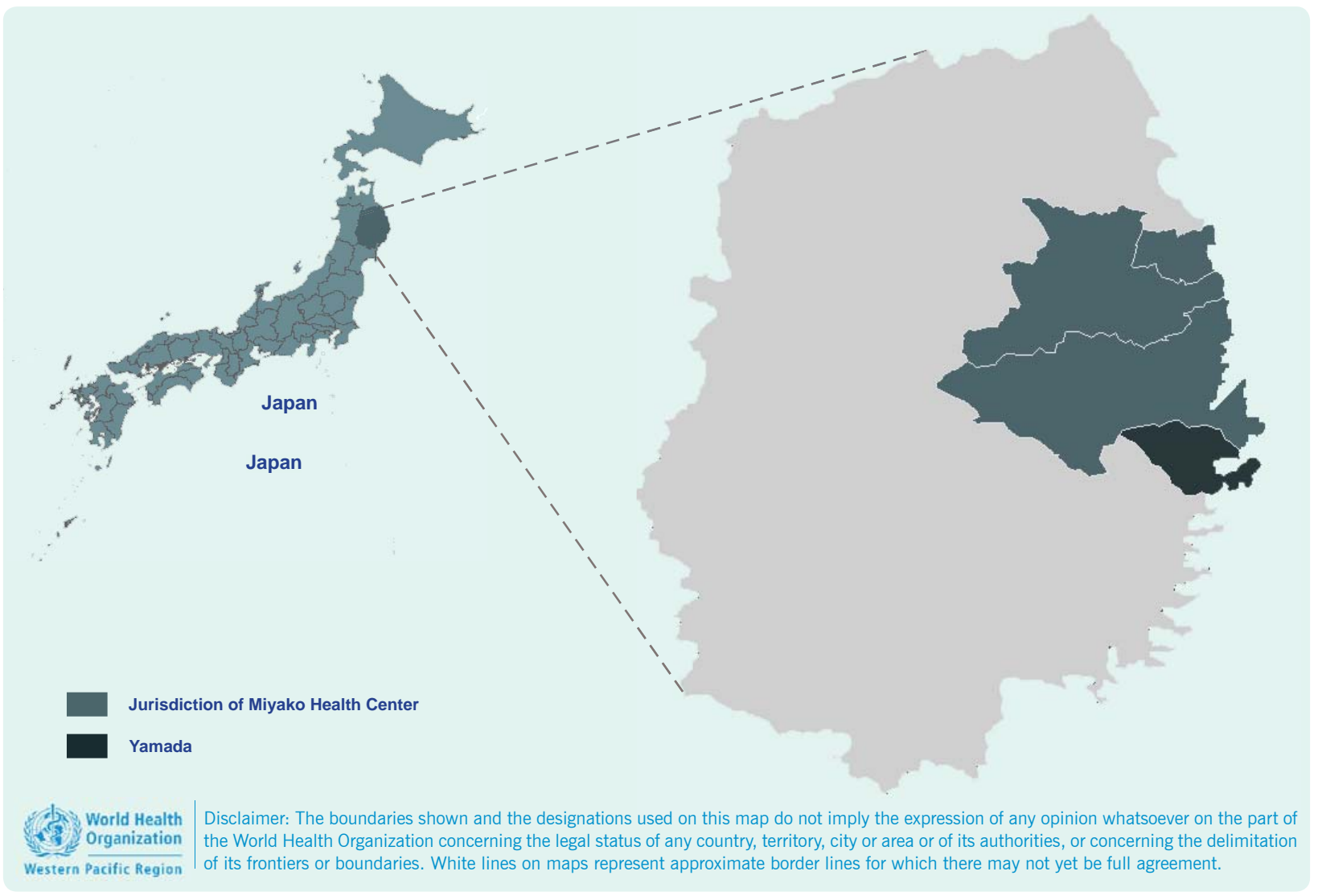

perspective. For these reasons, the need for registered dieticians to be proactively involved in dietary planning and support in disasters and to coordinate nutritional and dietary support has been indicated in recent years in Japan. ${ }^{1}$

Nationally registered dieticians provided nutritional and dietary support to people in evacuation shelters for about four months after the event in Yamada. These dieticians were hired either as temporary staff or seconded from other local governments. This paper discusses the lessons learnt from their role in the disaster response in Yamada, focusing on the general response only.

\section{ACTION}

From April to August 2011, the Yamada Nutrition Management Support Team (hereinafter "support team") was deployed to the Yamada and Miyako Public Health Center (hereinafter "public health centre") and tasked with nutritional and dietary support for evacuation shelters in Yamada, Iwate Prefecture, which was heavily damaged by the earthquake and tsunami. The support team studied the dietary conditions in shelters that prepared food and based on these studies, designed a system to meet the nutritional and balanced dietary needs of evacuees in shelters.

\section{Studies}

\section{Preliminary survey}

The public health centre received information on dietary issues of evacuation shelters in late March 2011 from nationally registered dieticians attached to public health teams dispatched from other prefectures. The nationally registered dieticians and food sanitation inspectors from the public health centre worked with the nationally registered dieticians in Yamada to survey the situation at eight selected shelters housing over 100 persons. They identified problems in food supply and management, menus and cooking equipment.

\section{Formation of support teams and study of dietary} conditions

After hearing the results of the preliminary survey, operations for food procurement, supply, management and coordination for evacuation shelters was moved from the Planning and General Affairs Department to the 
Health and Welfare Department in early April in Yamada. At the same time, with the support of the public health centre, a support team was formed of the nationally registered dieticians and others from Yamada, the public health centre, other local government and Dietetic Associations to coordinate nutritional and dietary support for all evacuation shelters. The support team consisted of seven to 11 staff depending on availability.

The support team assessed the dietary conditions of all evacuation shelters where some 4000 persons were living and identified the following problems from the perspective of nutritional and dietary support:

(1) distributed and supplied foods did not meet the nutritional and balanced dietary needs of evacuees;

(2) imbalance between distribution, delivery and ordering of food and burdens placed on cooks;

(3) lack of equipment adequate for preparing large quantities of food;
(4) unmanaged food stocks;

(5) inadequate consideration for sanitation in food storage; and

(6) event-cooking, where nongovernmental organizations (NGOs) and private companies provided a light meal on a one-off basis, occurred more often at larger shelters than smaller ones.

\section{Response}

From the findings of their studies of dietary conditions, the support team took the following three actions (Figure 2):

(1) Development and implementation of a menu-food matching system that was designed to meet the nutritional and balanced dietary needs of evacuees. This system consisted of three parts:

(a) Model menus

\section{Figure 2. Efforts of Yamada Nutritional Management Support Team, Yamada, Japan, April to August 2011}

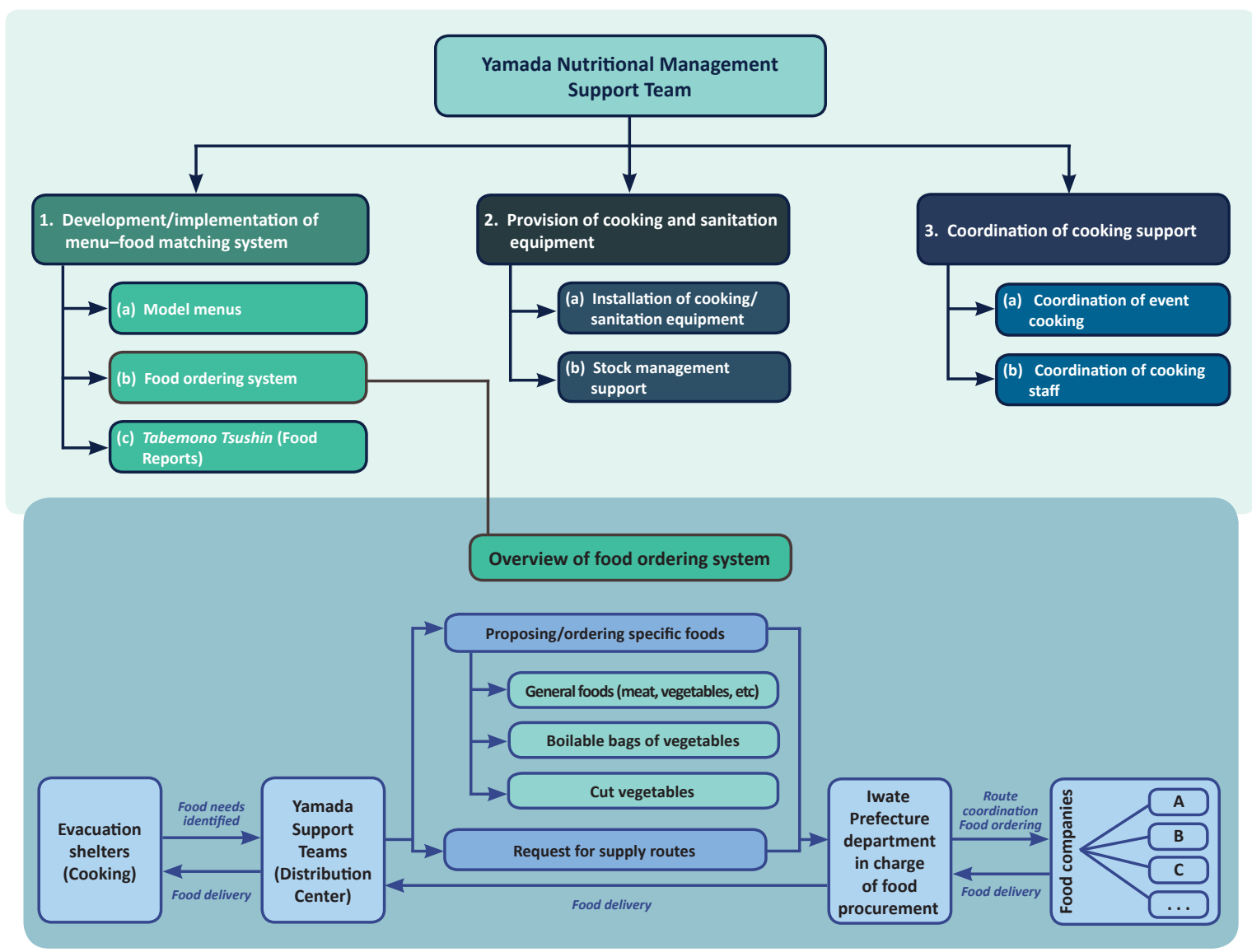


- Prepared weekly menus of meals anyone could easily prepare.

(b) Food ordering system

- Developed and put into use a sheet for calculating the amount of food required and tracking the amount of food distributed to evacuation shelters.

- Opened new routes (merchants) for boilable plastic bags of dishes and cut vegetables.

- Repeated a series of ordering of foods for a next week menu before delivering, distributing, cooking and serving.

(c) Tabemono Tsushin (Food Report)

- Provided information on alternative menus when foods for model menus were not delivered.

(2) Provision of cooking and sanitation equipment

(a) Installation of cooking and sanitation equipment

- Provided equipment necessary for cooking large quantities and managing food stocks.

- Installed cooking equipment in proportion to the number of persons living and working at evacuation shelters.

- Installed large refrigerator-freezers at food distribution centres and refrigerator-freezers at evacuation shelters.

(b) Stock management support

- Nationally registered dieticians managed food sanitation and food stocks for distribution to evacuation shelters.

- Dieticians made periodic rounds to check food stores.
(3) Coordination of cooking support

(a) Coordination of event-cooking

- Coordinated event-cooking to ensure distribution to all evacuation shelters rather than just large shelters.

(b) Coordination of cooking staff

- Matched volunteers from NGOs and elsewhere to cooking needs of evacuation shelters.

\section{OUTCOME}

During the long course of implementing the three actions above, the support teams noted the following benefits and challenges:

\section{Benefits}

(1) Menu-food matching system

(a) A food supply system that matched food ordering to food supply was run for 19 weeks (between 11 April and approximately 29 August). It provided a good balance of staples, main dishes, side dishes and soups.

(b) The menu repertoire expanded as boilable bags of dishes (Table 1) and Tabemono Tsushin (11 editions) were used in cooking.

(c) Cooking efficiency was improved and the burden placed on cooks was lessened by using model menus, boilable bags of food and packed lunches.

(2) Provision of large refrigerators and other equipment and stocks management support

(a) The menu repertoire expanded due to increased ability to handle raw meat and refrigerated foods.

(b) Sanitary management was improved by discarding foods beyond the expiration date and using refrigerator-freezers for foods. 
Table 1. Deliverable food items at evacuation shelters, Yamada, Japan, April to August 2011

\begin{tabular}{|c|c|}
\hline Food & Main items \\
\hline \multirow[t]{3}{*}{$\begin{array}{l}\text { Boilable bags of food } \\
\text { (dishes) }\end{array}$} & $\begin{array}{l}\text { Precooked foods in vacuum packs whether frozen, refrigerated or } \\
\text { preserved at room temperature }\end{array}$ \\
\hline & Can be warmed as is or naturally thawed in the bag before eating \\
\hline & $\begin{array}{l}\text { Examples: Potato salad, scrambled eggs, grilled fish, boiled fish, } \\
\text { steamed vegetables }\end{array}$ \\
\hline \multirow[t]{2}{*}{ Cut vegetables } & Vegetables precut according to cooking purpose \\
\hline & Examples: Onions, carrots, potatoes (for curry sauce) \\
\hline
\end{tabular}

(c) Food oversupplies and undersupplies were managed by checking stocks.

(3) Total coordination by dieticians proved useful to food supply, procurement, storage, supply and demand adjustments and cooking.

\section{Challenges}

(1) Because the menu-food matching system was run on a weekly basis, it was difficult to respond to the changes in evacuation shelter cooking needs in realtime.

(2) Cooking over a long period of time inevitably reduces taste quality of food.

(3) Food management at evacuation shelters has physical space limitations.

\section{DISCUSSION}

Given the recent history of large-scale natural disasters, Japan has compiled guidelines on nutritional and dietary support for evacuees in disaster in which the roles and functions of nationally registered dieticians are cited because of the skills they can provide. ${ }^{2}$ However, the disaster management plans of local governments, who are tasked with spearheading evacuee support, do not specify nutritional and dietary support to a significant degree, although they do specify the stockpiling and procurement of food. It is important that a system of coordination between disaster and risk management departments and health departments be created and maintained to provide nutritional and dietary support in disasters. ${ }^{1}$
The actions taken by the nationally registered dieticians in Yamada are a good example of how to address and respond to the aforementioned problems. Actions included logistical supply chain management that other departments normally handle in disaster management plans; distributing and cooking food; identifying food needs; and providing counselling and guidance on nutrition. The menu-food matching system made it possible to systematically and efficiently supply, divide and distribute food and provide well-balanced meals over several months. Moreover, the use of boilable bags of dishes and cut vegetables and efforts to coordinate supply routes ensured menu variety and effectively lessened the work for cooks.

However, in Yamada, food supplies managed in the menu-food matching system came erratically from various sources and routes. This augmented the burden placed on food management at evacuation shelters and resulted in considerable mismatching with the menus. In disasters, food and relief supplies are supplied by NGOs and private companies, not solely by the government. Fundamentally it is the affected government's role to coordinate disaster responses of assisting organizations, working together for maximum efficiency, coverage and effectiveness. ${ }^{3}$ Therefore, local governments should not only improve nutritional and dietary support but also provide coordination for disaster responses as a whole.

This report highlights the effectiveness and importance of having nationally registered dieticians coordinate the full process of nutritional and dietary support in this particular disaster response. In the interest of strengthening the disaster management systems of local governments, it is suggested that 
nutritional and dietary support and the roles of nationally registered dieticians be included in disaster management and preparedness plans.

\section{Conflicts of interests}

None declared.

Funding

None.

\section{Acknowledgements}

The efforts described in this report were implemented with the cooperation of many persons. The authors wish to express their heartfelt appreciation to the nationally registered dieticians and attending staff from Yamada, and all of the dieticians dispatched to provide support in Yamada from local governments across Japan and the Japan Dietetic Association and Iwate Dietetic Associations.

\section{References:}

1. Sudo N and Yoshiike N. What Should Health Professionals Do for a Disaster?: the Gap Between Expectation and Fact. Role of Administrative Dietitians in Health Emergencies. Journal of the National Institute of Public Health, 2008, 57(3):220-224 (http://ww.niph.go.jp/toshokan/home/ data/57-3/200857030005.pdf [in Japanese with English Abstract], accessed 2 November 2011).

2. Project to promote local Public Health in 2006, "Research project to consider registered dieticians' role to support nutrition and diet during health crisis management." Guideline to support nutrition and diet during health crisis management - what registered dietician at health centre to do during emergencies. Tokyo, Japan Public Health Association, 2007 (http://www. hc-kanri.jp/4 katudo/guideline.pdf [in Japanese], accessed 2 November 2011).

3. Humanitarian Charter and Minimum Standards in Humanitarian Response. Northampton, United Kingdom: The Sphere Project, 2011 (http://www.your-brochure-online.co.uk/sphere_handbook english_2011/html/, accessed 19 March 2012). 